\title{
Применение эквивалентной шуму разности температур для конгруэнтности фотоприемников сверхвысокой размерности на основе многослойных структур с квантовыми ямами
}

\author{
А.И. Козлов \\ ИФП СО РАН, Новосибирск, пр. Ак. Лаврентьева 13, тел: +7 (913) 762-65-90, aikozlov13@mail.ru.
}

DOI 10.34077/RCSP2021-150

Аналитические значения эквивалентной шуму разности температур (NETD) инфракрасного фотоприемника (ИК ФП) оценивается как отношение напряжения шума системы, включающей ИК фоточувствительный элемент (ФЧЭ) и канал считывания мультиплексора, к температурной чувствительности ИК ФЧЭ при квантовой эффективности ๆ:

$N E T D=\frac{U_{n}}{\frac{\partial U_{\text {sig }}}{\partial Q} \frac{\partial Q}{\partial T}} \approx \frac{U_{n} \Delta T}{\Delta U_{\text {sig }}}, \begin{aligned} & \text { где } U_{n}-\text { напализируемой системы, } \partial U_{\text {sig }} / \partial Q- \\ & \text { вольтовая чувствительность } \Phi Ч Э, Q \\ & \text { входной поток фотонов, } \partial Q / \partial T-\end{aligned}$ температурный градиент, $\Delta T$ - разность температур на входе оптической системы, $\Delta U_{s i g}$ - разность сигнального напряжения для данной разности $\Delta T[1-13]$.

Полученные аналитические значения NETD для многослойных структур с квантовыми ямами (МСКЯ) на GaAs/AlGaAs (1-4) и сверхрешеток (СР) на InAs/GaInSb (5,6) иллюстрируют Puc.1-2 [2диапазоне длин волн максимума спектральной чувствительности $\lambda_{\max } \approx 8.5-9.5 \mu \mathrm{m}$ МСКЯ ФП предоставляет хорошее (6-7) $\mathrm{mK}$ температурное разрешение, практически независимо от квантовой эффективности $\eta$, поскольку NETD определяется шумом фонового излучения [2]. NETD МСКЯ ФП при $\eta=0.05-0.2$ в диапазоне $\lambda_{\max }<10-11 \mu \mathrm{m}$ меньше, чем NETD СР ФП. При дальнейшем увеличении $\lambda_{\max }$ наблюдается рост NETD с существенным преимуществом для больших значений $\eta$ фотодетекторов (Puc. 1) $[2,3]$.

Мозаичный принцип - один из перспективных технологических подходов для достижения сверхвысокой размерности ИК ФП. Мозаичные фотоприемники (МФП) сверхвысокой размерности создают на базе прорывной технологии прецизионной микросборки фотоприемных кристаллов субмодулей меньших форматов, которые оптимальны для изготовления (Рис. 3) [6-7]. В работе исследованы зависимости основных характеристик ИК МФП сверхвысокой размерности от $\lambda_{\max }$, шага МСКЯ и формата субмодулей (Рuc.1-2) [5-8]. МФП сверхвысокой размерности обладают огромной, расширяющейся индустриальной сферой применения в перспективных исследованиях.

\section{Лumepamypa}

[1] G.Aad and ATLAS Collab. Eur. Phys. J.C. 2018. V.78, P.293-326.

[2] А.И. Козлов и др. Оптический журнал. 2016. Т.83, №9. С.64-

[3] А. И. Козлов. Оптический журнал. 2010. Т.77, №7. С.19-29.

[4] А. И. Козлов, М. А. Демьяненко и др. Оптический журнал. 2017. Т.84, №9. С.59-65.

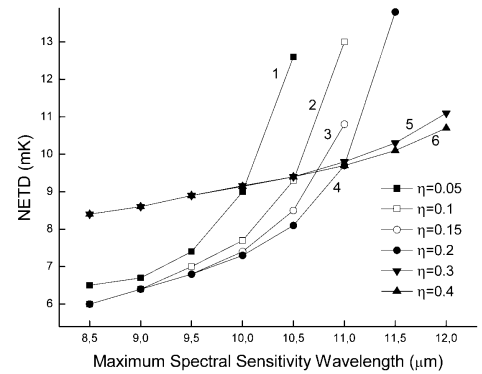

Рис.1. - Зависимости NETD

ИК ФП от $\lambda_{\max }$.

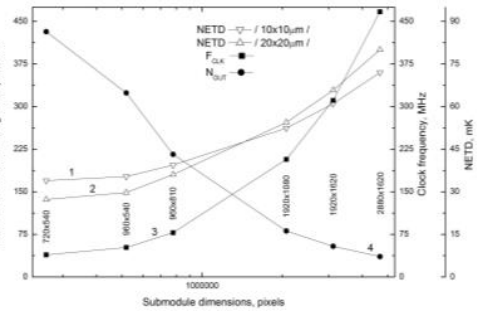

Рис.2. - Зависимости NETD, тактовой частоты и количества сигнальных выходов МФП от формата субмодулей и шага ФЧЭ.

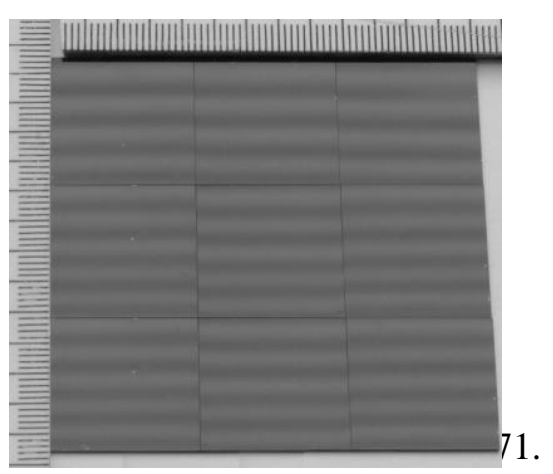

Рис.3. - Вид микросборки субмодулей в МФП $[7,9]$.

[5] А. И. Козлов и др. Тез. докл. Росс. конф. "ПОЛУПРОВОДНИКИ-2019". Т.2, С.445, С.447.

[6] А. И. Козлов, А. Р. Новоселов и др. Оптический журнал. 2018. Т.85, №2. С.60-66.

[7] А. И. Козлов, А. Р. Новоселов. Тез. докл. Росс. конф. "ФОТОНИКА-2019". С.152, С.171.

[8] А. И. Козлов и др. Оптический журнал. 2020. Т.87, №1. С.37-44.

[9] А. И. Козлов, М.А.Демьяненко и др. Патент РФ №2731460. Опубл. 03.09.20202. Бюл. №25.

[10] А. И. Козлов, А. Г. Клименко и др. Оптический журнал. 2014. Т.81, №3. С.35-43.

[11] А. И. Козлов, М. В. Якушев и др. Оптический журнал. 2014. Т.81, №7. С.39-45.

[12] А. Р. Новоселов. Автометрия. 2016. Т.52, №1. С.116-121.

[13] A. Rogalski. Progress in Quantum Electronics. 2012. V.36, P.342-473. 